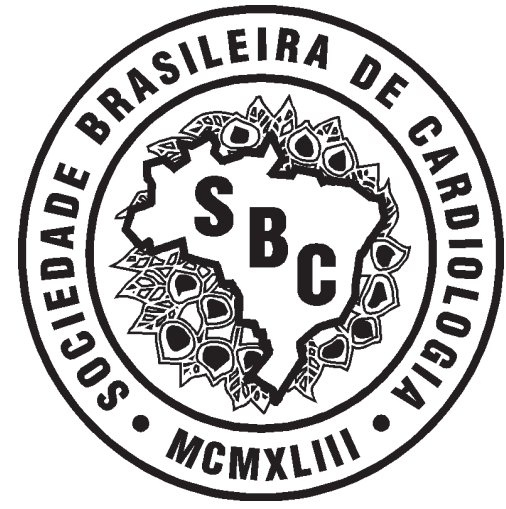

Diretriz de Apoio ao Suporte Avançado de Vida em Cardiologia - Código Azul - Registro de Ressuscitação Normatização do Carro de Emergência 


\title{
Diretriz de Apoio ao Suporte Avançado de Vida em Cardiologia - Código Azul - Registro de Ressuscitação Normatização do Carro de Emergência
}

\author{
Coordenador de Diretrizes e Normatizações da SBC:
}

Jorge Ilha Guimarães

Editor:

Sergio Timerman

Editores Associados:

Germano Emilio Conceição Souza,

Ana Paula Quilici,

Maria Margarita Castro Gonzalez

\author{
Membros \\ André Guanaes Gomes \\ Adriana M. Garcia \\ André Schmidt \\ Antonio P Mansur \\ Caio de Brito Vianna \\ DarioFerreira \\ Edison Paiva \\ Evandro Tinoco Mesquita \\ FátimaGil \\ Flávio Marques \\ Frederico Arnaud \\ Hugo Tannus \\ Jose Antonio F Ramires \\ Luis Hargreaves \\ Marcello Markus Paulista \\ ManuelF. Canesin \\ Marcia Martins \\ Paulo Miranda \\ Ricardo Tavares de Carvalho \\ Roberto Kalil Filho \\ Silvia Regina Rios Vieira \\ Tião Viana
}




\section{I - Código Azul}

\section{Introdução}

Durante os últimos 50 anos, com a introdução da ressuscitação cardiopulmonar (RCP), ocorreram muitos avanços no atendimento das emergências cardiovasculares e no suporte avançado de vida em cardiologia. Essas intervenções têm contribuído para restaurar a circulação e melhorar a sobrevivência de vítimas de paradas cardiorrespiratórias ${ }^{1}$.

Nos anos 50, Safar e cols ${ }^{2}$ e Elam e cols ${ }^{3}$ estudaram a ventilação boca a boca, observando como médicos neonatologistas utilizavam esta técnica para ressuscitarem recém nascidos. Por outro lado, em 1960, Kouwenhovenet e cols ${ }^{4}$ verificaram que compressões torácicas produziam significante pulso arterial. Foram, então, estabelecidos os passos críticos da moderna RCP: compressões torácicas e ventilação boca a boca.

O uso de corrente elétrica aplicada externamente, para tratar a fibrilação ventricular, foi descrito, primeiramente, em $1956^{5}$. Desde então, a capacidade dos desfibriladores para reverter ritmos cardíacos fatais apresentou um considerável progresso.

Hoje, para o sucesso do atendimento de uma vítima de parada cardiorrespiratória, são necessárias ressuscitação cardiopulmonar e desfibrilação precoces. Isso depende, em parte, da disponibilidade e funcionalidade do equipamento de reanimação, que deve estar pronto para uso imediato. Em 1994, King e cols ${ }^{6}$ observaram que, embora $82 \%$ das paradas cardiorrespiratórias tenham sido atendidas nos primeiros $3 \mathrm{~min}$, as restantes $18 \%$ foram atrasadas por desfibriladores quebrados e ausência de laringoscópios ou de tubos endotraqueais. ${ }^{7}$ São também citados na literatura, como interferências desfavoráveis na evolução desses pacientes, tempo de início da ressuscitação, hipotensão prévia, sepse, escore de APACHE II elevado na admissão, duração da ressuscitação ${ }^{8}$, horário da parada cardiorrespiratória e ritmo cardíaco inicial ${ }^{9}$.

O sucesso no atendimento de uma parada cardiorrespiratória (PCR) depende ainda do treinamento da equipe, $\mathrm{o}$ que pode ser feito através dos cursos de Suporte Avançado de Vida em Cardiologia e Suporte Básico de Vida.

O Instituto do Coração (InCor), por meio da Comissão Interna de Ressuscitação Cardiopulmonar, padronizou o atendimento das PCRs ocorridas fora das Unidades de Terapia Intensiva, Serviço de Emergência ou Centro Cirúrgico, de forma a minimizar a demora no atendimento e resultante perda de vidas humanas. De igual forma, foi normatizado, através do modelo Utstein, o registro das PCR, para estudo da sobrevida desses pacientes.

Essa mesma normatização foi adotada na presente Diretriz. Prevê-se a estruturação de uma equipe composta por 3 médicos e 2 enfermeiros, para atender qualquer PCR que venha a ocorrer em unidades ditas não-críticas, ou seja, que não sejam de terapia intensiva, pronto socorro ou centro cirúrgico. Em diversos centros médicos do mundo, esse tipo de padronização de atendimento das PCR é denominado Código Azul, nome também adotado nesta Diretriz.

\section{Objetivos do Código Azul}

1-Estudar a incidência e a forma como são atendidas as paradas cardiorrespiratórias, nas diversas instituições médicas; 2 - sistematizar o atendimento de pacientes com suspeita de PCR, de forma a abreviar, ao máximo, o acesso ao suporte básico e avançado de vida, sempre que se fizer necessário; 3 - aumentar a taxa de sobrevida em pacientes com PCR; 4 - diminuir os custos hospitalares e sociais das PCR.

O Código Azul deverá ocorrer em 3 etapas:

$1^{\text {a }}$. etapa: levantamento, análise, treinamento de equipe piloto, organização e definição dos demais procedimentos necessários.

$\mathbf{2}^{\mathbf{a}}$. etapa: treinamento dos diversos níveis de funcionários da instituição, conforme seu papel no Código Azul e corrente de sobrevida, implantação de rotinas e procedimentos pertinentes.

$3^{\text {a }}$. etapa: acompanhamento, manutenção e atualizações dos procedimentos periodicamente.

\section{Etapa1}

Fase 1 - Convocação dos responsáveis pelas unidades/áreas da instituição para explanação e apresentação da Implantação do Código Azul (ativação de um comitê interno de RCP)

Fase 2 - Atividade 1: levantamento retrospectivo de dados sobre casos de parada cardiorrespiratória da instituição (Registro). No caso de instituições que não possuam nenhum tipo de registro das paradas cardiorrespiratórias, esta primeira fase será realizada no projeto de implementação do Código Azul, com o objetivo de conhecer essa incidência por unidade, além de diagnosticar dificuldades e necessidades de cada setor. Será preenchido um formulário (anexo I), baseado no Método de Utstein, que analisará quatro variáveis: hospitalares, dos pacientes, da parada cardiorrespiratórias e de evolução. Formulário a ser preenchido por enfermeiro treinado, após visita diária nas diferentes unidades da instituição, em conjunto com o médico que fez o atendimento e a revisão dos prontuários dos pacientes vítimas de parada cardiorrespiratórias. O tempo estimado para realização dessa $1^{\text {a }}$. etapa não deve ser maior que 30 dias.

- Atividade 2: padronização dos carros de emergência. Deverá ser realizada uma análise do funcionamento dos carros de emergência através de um formulário (anexo II), com o objetivo de determinar as deficiências desse equipamento e a adequação de seu uso, nas diferentes unidades. O formulário será preenchido por um enfermeiro, através de visita diária pelas diferentes unidades do hospital. Posteriormente, será estabelecido um carro de atendimento de emergências padrão. A padronização dos carros de emergência baseia-se nas Normas da American Heart Association para medicações e equipamentos para ressuscitação cardiopulmonar $^{11}$. 
- Atividade 3: tabulação e análise de dados. Deverá ser formado um banco de dados simplificado para análise prévia e a tabulação será realizada por um digitador. Recomenda-se o sistema do NRCPR ou do ReCAPi InCor.

Fase 3 - Comissão Código Azul: deverá ser formada uma comissão Código Azul, envolvendo representantes de diferentes áreas do hospital, para determinar os seguintes itens: 1 - composição da equipe de atendimento do código azul; 2 - forma de treinamento destas equipes; $\mathbf{3}$ - modo de funcionamento: por escala, fixo ou rotativo; 4 - funcionamento, disposição e reposição dos carros de emergência; 5 - registro das paradas cardiorrespiratórias; 6 - levantamento das necessidades de adaptação logística fundamentais para a implementação do Código Azul.

Essa comissão deverá decidir também: a) aquisição de novos equipamentos (beeper, palm, desfibriladores externos automáticos - DEA). O método que será utilizado para o acionamento da equipe de Código azul deverá ser discutido sempre com a divisão de informática da instituição; b) reestruturação de elevadores, pela necessidade de sistema de identificação de chamada para o plantonista do Código Azul, que possibilite um transporte rápido e prioritário em direção ao local do atendimento. $\mathrm{O}$ sistema ideal é baseado no uso de cartão magnético, que pode ser passado de plantonista para plantonista. Este sistema pode ser implantado após modificação dos softwares dos elevadores e envolve a Unidade de Administração Predial; c) ressincronização dos relógios de toda a Instituição, medida que resolverá problemas quanto ao registro exato das atividades de ressuscitação cardiorrespiratória, bem como de todas as outras atividades da instituição, incluindo horários de chegada e saída de plantões. O tempo estimado para realização desta etapa é de 60 dias.

Fase 4 - Treinamento dos funcionários - Para o sucesso da implementação do código azul, é necessário treinamento, não apenas dos membros que irão compor a equipe de atendimento direto ao paciente, como também de todos os funcionários que atuarão, direta e indiretamente, na sua efetivação. Assim, por exemplo, tanto um recepcionista como um ascensorista devem estar treinados para reconhecer e prestar primeiros socorros em situações de emergência cardiovascular, bem como agir rapidamente para que a equipe de atendimento (Equipe do Código Azul), chegue o mais rapidamente possível ao local. Entende-se, no entanto, que a prioridade para iniciar o processo de implantação é o treinamento dos componentes da escala de plantão de Código Azul: a) médicos-plantonistas do Departamento de Emergência; b) médicos-plantonistas da enfermaria; c) médicoresidente de plantão na enfermaria; d) enfermeiros, em número e unidade a serem definidos pelo departamento de enfermagem.

No que tange aos outros profissionais não envolvidos diretamente no atendimento, são propostos três níveis de treinamento: Nível 3: treinamento de médicos, enfermei- ros, fisioterapeutas e dentistas em Suporte Avançado de Vida em Cardiologia e Suporte Básico de Vida para profissionais de saúde. Será discutida a necessidade de treinamento em Suporte Avançado de Vida em Pediatria. Nível 2: treinamento de nutricionistas, auxiliares de enfermagem, e professores de educação física em Suporte Básico de Vida para profissionais de saúde. Nível 1: treinamento de pessoal de serviços administrativos em Suporte Básico de Vida para leigos.

O período de tempo estimado para efetivar esta fase é de 90 dias.

Fase 5 - Análise e determinações dos procedimentos para efetivação da $2^{\text {a }}$ Etapa do Código Azul

Depois de efetivada a $1^{\circ}$ etapa, composta de 4 fases, o Código Azul deverá oferecer treinamento contínuo e sistematizado para as pessoas envolvidas no atendimento de parada cardiorrespiratória, assim como avaliação periódica e capacitação de novos funcionários, de forma a não quebrar a corrente de atendimento implantado.

Para tanto, a comissão do Código Azul da instituição deverá analisar e definir a forma de procedimento necessária para iniciar a $2^{\mathrm{a}}$ etapa.

Relatórios regulares serão realizados pela equipe responsável pelo registro das PCR, fornecendo o feedback necessário para o aprimoramento contínuo do projeto.

\section{II - Padronização dos Carros de Emergência}

Médicos e enfermeiros devem estar preparados para atender, de forma sistematizada e padronizada, uma situação de emergência. Para que isso ocorra, o treinamento da equipe é fundamental, e todo o material necessário para esse momento deve estar disponível de forma imediata.

Com base nessa necessidade, propõe-se a padronização dos carros de emergência, objetivando homogeneizar o conteúdo e quantidade de material dos carrinhos nas diferentes unidades, retirando o desnecessário e acrescentando o indispensável, de forma a agilizar o atendimento de emergência e reduzir o desperdício.

Os tópicos a serem consideradas nessa homogeneização são - idade da vítima: adulto e/ou infantil; - local do evento: unidade de internação, pronto socorro, UTI, CC, unidade ambulatorial, hemodinâmica, entre outros.

Baseado no The Code Cart Statement, AHA Scientific Statement, o conteúdo dos carros foi dividido em níveis de prioridade: Nível I- itens essenciais, que devem estar disponíveis IMEDIATAMENTE; Nível II- itens altamente recomendados, que devem estar disponíveis, no máximo, em 15 minutos; Nível III - itens recomendados, mas opcionais.

Caso as drogas e equipamentos classificados como nível 2 não possam estar disponíveis NA UNIDADE para acesso em ATÉ 15 minutos, devem PERMANECER nos carros de emergência.

A quantidade de drogas e equipamentos deve ser estipulada conforme necessidade da área e rotina institucional. 


\section{Normatização dos carros de emergência para pacientes adultos}

\section{Local: Intra-hospitalar: Unidade de Internação}

Definições de prioridades - Nível 1 - Item essencial. Deve estar prontamente disponível, com resposta imediata; Nível 2 - Item altamente recomendável -. Deve estar disponível, no máximo em 15 minutos, variando conforme necessidade do local e protocolos; Nivel 3 - Item recomendado, mas opcional

\begin{tabular}{|c|c|c|}
\hline Finalidade & Pacientes Adultos & Nível de Prioridade \\
\hline Avaliação e Diagnóstico & $\begin{array}{l}\text { Desfibrilador externo automático } \\
\text { Material de proteção (luvas, máscaras e óculos) } \\
\text { Monitor/desfibrilador com marcapasso externo, com monitorização nas pás, mínimo } 3 \text { derivações, } \\
\text { onda bifásica } \\
\text { Oxímetro de pulso } \\
\text { Dextro } \\
\text { Gerador de marcapasso }\end{array}$ & $\begin{array}{l}1 \\
1 \\
1 \\
2 \\
2 \\
3 \\
3\end{array}$ \\
\hline Controle de Vias Aéreas & $\begin{array}{l}\text { Cânula orofaríngea }\left(n^{\circ} 3 \text { e } 4\right) \\
\text { Bolsa valva-máscara com reservatório de } \mathrm{O}^{2} \\
\text { Tubo endotraqueal }(6,0 \text { a } 9,0) \\
\text { Cânula para traqueostomia }(6,0 \text { a } 9,0) \\
\text { Laringoscópio com lâmina curva } \mathrm{n}^{\circ} 3 \text { e } 4 \\
\text { Máscara de oxigênio com reservatório } \\
\text { Cânula nasal tipo óculos } \\
\text { Umidificador } \\
\text { Nebulizador } \\
\text { Extensão para nebulizador } \\
\text { Extensão de PVC para oxigênio } \\
\text { Cânula de aspiração flexível no }{ }^{\circ} 12,10 \\
\text { Fixador de cânula orotraqueal } \\
\text { Sonda nasogástrica no } 16,18 \\
\text { Detector esof́gico (ou outro dispositivo para confirmação secundária) } \\
\text { Máscara laríngea adulto }\end{array}$ & $\begin{array}{l}1 \\
1 \\
1 \\
1 \\
1 \\
1 \\
1 \\
1 \\
1 \\
1 \\
1 \\
1 \\
1 \\
2 \\
3 \\
3 \\
3\end{array}$ \\
\hline $\begin{array}{l}\text { Acesso Vascular e } \\
\text { Controle Circulatório }\end{array}$ & $\begin{array}{l}\text { Jelco } \mathrm{n}^{\circ} 14,16,18 \text { e } 20,22 \\
\text { Torneirinhas } \\
\text { Conjunto de perfusão } \\
\text { Agulha de intracath (para tamponamento e pneumotórax hipertensivo) } \\
\text { SF } 1000 \mathrm{ml} \text {, Ringer Lactato } 1000 \mathrm{ml}, \text { SG } 5 \% 500 \mathrm{ml} \\
\text { Equipo macrogotas } \\
\text { Equipo para hemoderivados } \\
\text { Bureta } \\
\text { Seringa de } 3 \mathrm{ml}, 5 \mathrm{ml}, 10 \mathrm{ml}, 20 \mathrm{ml} \\
\text { Agulha } 36 \mathrm{X} 12 \text { ou } 36 \mathrm{X} 10 \\
\text { Frasco a vácuo } \\
\text { Gases } \\
\text { Micropore }\end{array}$ & $\begin{array}{l}1 \\
1 \\
1 \\
1 \\
1 \\
1 \\
1 \\
1 \\
1 \\
1 \\
1 \\
1 \\
1\end{array}$ \\
\hline Medicamentos & $\begin{array}{l}\text { Água destilada } 10 \mathrm{ml} \\
\text { Água destilada } 250 \mathrm{ml} \\
\text { Água destilada } 500 \mathrm{ml} \text { (para nitroglicerina) } \\
\text { Aspirina } 300 \mathrm{mg} \\
\text { Atropina } 1 \mathrm{mg} \\
\text { Adrenalina } 1 \mathrm{mg} \\
\text { Amiodarona } \\
\text { Lidocaína } \\
\text { Adenosina } \\
\text { B-bloqueador } \\
\text { Nitroglicerina } \\
\text { Nitroprussiato } \\
\text { Cloreto de cálcio } \\
\text { Gluconato de cálcio } \\
\text { Sulfato de magnésio } \\
\text { Procainamida } \\
\text { Bicarbonato de sódio } \\
\text { Glicose } 50 \% \\
\text { Furosemida } \\
\text { Broncodilatador } \\
\text { Aminofilina } \\
\text { Diempax } \\
\text { Dormonid/Fentanil (sedação em geral) } \\
\text { Morfina } \\
\text { Dobutamina } \\
\text { Dopamina } \\
\text { Naloxone } \\
\text { Diltiazem } \\
\text { Verapamil } \\
\text { Manitol } \\
\text { Isoproterenol }\end{array}$ & $\begin{array}{l}1 \\
1 \\
1 \\
1 \\
1 \\
1 \\
1 \\
1 \\
1 \\
1 \\
1 \\
1 \\
1 \\
1 \\
1 \\
1 \\
1 \\
1 \\
1 \\
1 \\
2 \\
2 \\
2 \\
2 \\
2 \\
2 \\
3 \\
3 \\
3 \\
3 \\
3\end{array}$ \\
\hline
\end{tabular}




\section{Local: Intra-hospitalar: Unidade de Terapia Intensiva e Pronto Socorro}

\begin{tabular}{|c|c|c|}
\hline Finalidade & Pacientes Adultos & Prioridade \\
\hline \multirow[t]{5}{*}{ Avaliação e Diagnóstico } & Monitor/desfibrilador com marcapasso externo, com monitorização nas pás, mínimo 3 derivações, onda bifásica & 1 \\
\hline & Material de proteção (luvas, máscaras e óculos) & 1 \\
\hline & Oxímetro de pulso & 1 \\
\hline & Dextro & 2 \\
\hline & Gerador de marcapasso & 3 \\
\hline \multirow[t]{18}{*}{ Controle de Vias Aéreas } & Cânula orofaríngea (nº 3 e 4$)$ & 1 \\
\hline & Bolsa valva-máscara com reservatório de $\mathrm{O}^{2}$ & 1 \\
\hline & Máscara facial tamanho adulto & 1 \\
\hline & Tubo endotraqueal $(6,0$ a 9,0$)$ & 1 \\
\hline & Cânula para traqueostomia $(6,0$ a 9,0$)$ & 1 \\
\hline & Laringoscópio com lâmina curva no 3 e 4 & 1 \\
\hline & Máscara de oxigênio com reservatório & 1 \\
\hline & Cânula nasal tipo óculos & 1 \\
\hline & Umidificador & 1 \\
\hline & Nebulizador & 1 \\
\hline & Extensão para nebulizador & 1 \\
\hline & Extensão de PVC para oxigênio & 1 \\
\hline & Cânula de aspiração flexível n 12,10 & 1 \\
\hline & Fixador de cânula orotraqueal & 1 \\
\hline & Sonda nasogástrica $\mathrm{n}^{\circ} 16,18$ & 2 \\
\hline & Detector esofágico (ou outro dispositivo para confirmação secundária) & 3 \\
\hline & Máscara laríngea adulto & 3 \\
\hline & $\begin{array}{l}\text { Via aérea alternativa (um ou mais dos seguintes itens: agulha para cricotireostomia, conjunto para } \\
\text { traqueostomia percutânea) }\end{array}$ & 3 \\
\hline \multirow{13}{*}{$\begin{array}{l}\text { Acesso Vascular } \\
\text { e Controle Circulatório }\end{array}$} & Jelco $\mathrm{n}^{\circ} 14,16,18$ e 20,22 & 1 \\
\hline & Torneirinha & 1 \\
\hline & Conjunto de perfusão & 1 \\
\hline & Agulha de intracath (para tamponamento e pneumotórax hipertensivo) & 1 \\
\hline & SF $1000 \mathrm{ml}$, Ringer Lactato $1000 \mathrm{ml}$, SG $5 \% 500 \mathrm{ml}$ & 1 \\
\hline & Equipo macrogotas & 1 \\
\hline & Equipo para hemoderivados & 1 \\
\hline & Bureta & 1 \\
\hline & Seringa de $3 \mathrm{ml}, 5 \mathrm{ml}, 10 \mathrm{ml}, 20 \mathrm{ml}$ & 1 \\
\hline & Agulha $36 \times 12$ ou $36 \times 10$ & 1 \\
\hline & Frasco a vácuo & 1 \\
\hline & Gase & 1 \\
\hline & Micropore & 1 \\
\hline \multirow{32}{*}{ Medicamentos } & Água destilada $10 \mathrm{ml}$ & 1 \\
\hline & Água destilada $250 \mathrm{ml}$ & 1 \\
\hline & Água destilada 500ml (para nitroglicerina) & 1 \\
\hline & Aspirina 300mg & 1 \\
\hline & Atropina 1mg & 1 \\
\hline & Adrenalina $1 \mathrm{mg}$ & 1 \\
\hline & Amiodarona & 1 \\
\hline & Lidocaína & 1 \\
\hline & Adenosina & 1 \\
\hline & B-bloqueador & 1 \\
\hline & Nitroglicerina & 1 \\
\hline & Nitroprussiato & 1 \\
\hline & Cloreto de cálcio & 1 \\
\hline & Gluconato de cálcio & 1 \\
\hline & Sulfato de magnésio & 1 \\
\hline & Procainamida & 1 \\
\hline & Bicarbonato de sódio & 1 \\
\hline & Glicose $50 \%$ & 1 \\
\hline & Furosemida & 1 \\
\hline & Broncodilatador & 1 \\
\hline & Aminofilina & 2 \\
\hline & Diempax & 2 \\
\hline & Dormonid/Fentanil (sedação em geral) & 2 \\
\hline & Morfina & 2 \\
\hline & Dobutamina & 2 \\
\hline & Dopamina & 2 \\
\hline & Norepinefrina & 2 \\
\hline & Naloxone & 3 \\
\hline & Diltiazem & 3 \\
\hline & Verapamil & 3 \\
\hline & Manitol & 3 \\
\hline & Isoproterenol & 3 \\
\hline
\end{tabular}


Arq Bras Cardiol

volume 81, (Suplemento IV), 2003

\section{Normatização dos Carros de Emergência para Pediatria}

\section{Local: Intra-hospitalar: Unidade de Internação, ProntoSocorroe Unidade de Terapia Intensiva}

\begin{tabular}{|c|c|c|}
\hline Finalidade & Pacientes Pediátricos & Nível de Prioridade \\
\hline \multirow[t]{4}{*}{ Avaliação e Diagnóstico } & $\begin{array}{l}\text { Monitor/desfibrilador com pás infantil, marcapasso externo infantil, com monitorização nas pás, } \\
\text { mínimo } 3 \text { derivações, onda bifásica }\end{array}$ & 1 \\
\hline & Material de proteção (luvas, máscaras e óculos) & 1 \\
\hline & Oxímetro de pulso & 2 \\
\hline & Dextro & 2 \\
\hline \multirow[t]{17}{*}{ Controle de Vias Aéreas } & Cânula orofaríngea $\left(\mathrm{n}^{\circ} 00,0,1,2\right)$ & 1 \\
\hline & Bolsa valva-máscara com reservatório de $\mathrm{O}^{2}$ & 1 \\
\hline & Máscara facial tamanho neonato, bebê, criança & 1 \\
\hline & Tubo endotraqueal $(2,5$ a 7,0$)$ & 1 \\
\hline & Laringoscópio com lâmina reta $\left(n^{\circ} 00,0,1,2\right)$ & 1 \\
\hline & Máscara de oxigênio com reservatório & 1 \\
\hline & Cânula nasal tipo óculos & 1 \\
\hline & Umidificador & 1 \\
\hline & Nebulizador & 1 \\
\hline & Extensão para nebulizador & 1 \\
\hline & Extensão de PVC para oxigênio & 1 \\
\hline & Cânula de aspiração flexível n ${ }^{\circ} 6,8$ & 1 \\
\hline & Fixador de cânula orotraqueal & 1 \\
\hline & Sonda nasogátrica $\mathrm{n}^{\circ} 6,8$ & 2 \\
\hline & Detector de $\mathrm{CO}^{2}$ (ou outro dispositivo para confirmação secundária) & 2 \\
\hline & $\begin{array}{l}\text { Via aérea alternativa (um ou mais dos seguintes itens: agulha para cricotireostomia, conjunto para } \\
\text { traqueostomia percutânea) }\end{array}$ & 3 \\
\hline & Máscara laríngea & 3 \\
\hline \multirow{14}{*}{$\begin{array}{l}\text { Acesso Vascular } \\
\text { e Controle Circulatório }\end{array}$} & Jelco $\mathrm{n}^{\circ} 22,24$ & 1 \\
\hline & Agulha de punção intra-óssea & 1 \\
\hline & Torneirinha & 1 \\
\hline & Conjunto de perfusão & 1 \\
\hline & Agulha de intracath (para tamponamento e pneumotórax hipertensivo) & 1 \\
\hline & SF $1000 \mathrm{ml}$, Ringer Lactato $1000 \mathrm{ml}, \mathrm{SG} 5 \% 500 \mathrm{ml}$ & 1 \\
\hline & Equipo macrogotas & 1 \\
\hline & Equipo para hemoderivados & 1 \\
\hline & Bureta & 1 \\
\hline & Seringa de $3 \mathrm{ml}, 5 \mathrm{ml}, 10 \mathrm{ml}, 20 \mathrm{ml}$ & 1 \\
\hline & Agulha $36 \times 12$ ou $36 \times 10$ & 1 \\
\hline & Frasco a vácuo & 1 \\
\hline & Gases & 2 \\
\hline & Micropore & 1 \\
\hline \multirow[t]{32}{*}{ Medicamentos } & Água destilada $10 \mathrm{ml}$ & 1 \\
\hline & Água destilada $250 \mathrm{ml}$ & 1 \\
\hline & Água destilada 500ml (para nitroglicerina) & 1 \\
\hline & Aspirina 300mg & 1 \\
\hline & Atropina $1 \mathrm{mg}$ & 1 \\
\hline & Adrenalina 1mg & 1 \\
\hline & Amiodarona & 1 \\
\hline & Lidocaína & 1 \\
\hline & Adenosina & 1 \\
\hline & B-bloqueador & 1 \\
\hline & Nitroglicerina & 1 \\
\hline & Nitroprussiato & 1 \\
\hline & Cloreto de cálcio & 1 \\
\hline & Gluconato de cálcio & 1 \\
\hline & Sulfato de magnésio & 1 \\
\hline & Procainamida & 1 \\
\hline & Furosemida & 1 \\
\hline & Bicarbonato de sódio & 1 \\
\hline & Glicose $50 \%$ & 1 \\
\hline & Broncodilatador & 1 \\
\hline & Aminofilina & 2 \\
\hline & Diempax & 2 \\
\hline & Dormonid/Fentanil (sedação em geral) & 2 \\
\hline & Morfina & 2 \\
\hline & Dobutamina & 2 \\
\hline & Dopamina & 2 \\
\hline & Noradrenalina & 2 \\
\hline & Naloxone & 3 \\
\hline & Diltiazem & 3 \\
\hline & Verapamil & 3 \\
\hline & Manitol & 3 \\
\hline & Isoproterenol & 3 \\
\hline
\end{tabular}




\section{III - Registro de Ressuscitação Intra-hospitalar}

\section{Introdução}

O grupo tarefa de Utstein da Aliança Internacional dos Comitês de Ressuscitação (ILCOR) tem realizado um extraordinário esforço para desenvolver documentos vitais para a elaboração de estratégias frente a uma PCR. Em 1996, constituiu-se oficialmente o Conselho Latino-Americano de Ressuscitação(CLAR), organismo de integração ao ILCOR. Em 1998, o CLAR juntou seus esforços aos da Fundação Interamericana de Cardiologia (FIC), na área de Emergências Cardiovasculares e de Ressuscitação Cardiopulmonar (RCP). Atualmente, o CLAR constitui o Comitê Científico da FIC e participou, ativamente, durante os anos de 1999-2000, no processo de elaboração das Guias Internacionais de Ressuscitação-2000 ${ }^{12}$.

O modelo Utstein para registrar paradas cardíacas surgiu na conferência de 1990, na antiga cidade desse nome, numa ilha perto de Stavanger, Noruega, com participação de representantes da American Heart Association (AHA), do Conselho Europeu de Ressuscitação (ERC), a FIC, a Heart and Stroke Foundation of Canadá(HSFC), o Conselho Sul Africano de Ressuscitação e o Conselho Australiano de Ressuscitação ${ }^{12-19}$. Na ocasião, havia a preocupação com uma comparação adequada entre os resultados dos esforços relacionados com ressuscitação, efetuados tanto em diferentes países, como dentro de um mesmo país, por falta de definições e metodologias uniformes. A partir de então, muitos investigadores e diretores de sistemas têm adotado as planilhas, estilo e nomenclatura Utstein para registrar os resultados da ressuscitação pré-hospitalar. O êxito dessa iniciativa propiciou a padronização dos modelos internacionais para registrar os resultados da ressuscitação pediátri$\mathrm{ca}^{20}$ e para a ressuscitação experimental (laboratorial) ${ }^{21}$.

Esse processo de padronização teve prosseguimento com a inclusão da ressuscitação intra-hospitalar do adulto, dentro dos acordos internacionais para seu registro. Tais pautas e recomendações podem melhorar o desenho científico dos projetos de investigação e aumentar a utilidade clínica dos estudos publicados ${ }^{22}$, de forma a proporcionar evidências consistentes e confiáveis, nas quais poder-se-ão basear as decisões dos tratamentos.

\section{Ressuscitação Intra-hospitalar}

A ressuscitação intra-hospitalar apresenta um desafio único para a investigação e a avaliação. Uma parada cardíaca é definida, no estilo Utstein, como " parada da atividade mecânica cardíaca... confirmada pela ausência de pulso detectável, inconsciência e apnéia (ou respirações agônicas)" 11-19. Sabe-se, entretanto, que um paciente pode ter tido muitos graus de disfunções cardíacas e respiratórias, não caracterizadas como paradas cardíacas, tais como hipotensão ou choque. Seu estado respiratório pode variar de normal a agônico, ou o paciente pode estar em ventilação mecânica.

O paciente que necessita ressuscitação pode apresentar co-doenças que podem ou não influenciar no resultado da ressuscitação. Essas condições co-patológicas podem não estar relacionadas com o resultado da ressuscitação (como na histerectomia por fibromas uterinos), moderadamente relacionadas (caso de pneumonia pneumocócica aguda), ou fortemente relacionadas (como em edema pulmonar agudo, após infarto do miocárdio). Ademais, as condições co-patológicas e condições pré-existentes podem variar enormemente na sua gravidade. Assim, por exemplo, uma pneumonia pneumocócica aguda pode variar na extensão do compromisso do órgão envolvido e na sua gravidade. Entretanto, quase todas as publicações de registros intrahospitalares não incluem a magnitude das condições copatológicas.

Para melhorar os registros de ressuscitação intra-hospitalar, a força tarefa de Utstein e o comitê de padronização da SBC identificaram quatro grupos de variáveis que requerem maior definição: variáveis do hospital, do paciente, do evento e dos resultados (acompanhamento).

O quadro 1 enumera as variáveis que a força tarefa recomenda que sejam registradas. Ao selecionar as variáveis requeridas, buscou incluir aquelas para as quais existem evidências de uma associação com diferenças nas taxas de sobrevivência. Ao mesmo tempo, este quadro define as variáveis e proporciona instruções ou comentários para seu uso. 


\begin{tabular}{|c|c|c|c|}
\hline \multicolumn{4}{|c|}{ Quadro 1 - Dados que devem ser coletados na planilha de registro de ressuscitação cardiopulmonar intra-hospitalar. } \\
\hline & Definição & $\begin{array}{l}\text { Prioridade } \\
\text { (essencial/desejável) }\end{array}$ & Instruções ou Comentários \\
\hline \multicolumn{4}{|l|}{ Variáveis do paciente } \\
\hline $\begin{array}{l}\text { Nome do paciente (coletar para os } \\
\text { registros médicos, não para informe } \\
\text { de dados) }\end{array}$ & $\begin{array}{l}\text { Alguém que ocupa uma cama de hospital. } \\
\text { Não requer uma duração de ocupação } \\
\text { (ex > } 24 \text { horas) }\end{array}$ & Essencial & $\begin{array}{l}\text { Tabule separadamente pacientes } \\
\text { ambulatoriais que tiveram eventos } \\
\text { dentro do hospital; pacientes com } \\
\text { eventos dentro do hospital, mas cuja } \\
\text { parada ocorreu originalmente fora do } \\
\text { hospital. Deve-se respeitar sigilo sobre } \\
\text { os dados dos pacientes. }\end{array}$ \\
\hline Identificador dos pacientes & $\begin{array}{l}\text { Um registro único para permitir o seguimento } \\
\text { de todos os registros do hospital e } \\
\text { auditorias posteriores. }\end{array}$ & Essencial & $\begin{array}{l}\text { Número do prontuário ou número de } \\
\text { identidade }\end{array}$ \\
\hline Data de nascimento & Auto-explicativo & Essencial & Registre como dia/mês/ano \\
\hline Data de admissão & Auto-explicativo & Essencial & Registre como dia/mês/ano \\
\hline Idade & Auto-explicativo & Essencial & Registre como anos. \\
\hline Sexo & Auto-explicativo & Essencial & Registre como masculino, feminino. \\
\hline Estatura & Essencial para lactantes e crianças & Essencial & Registre em escala métrica. \\
\hline Peso & Essencial para lactantes e crianças & Essencial & Registre em Kg. \\
\hline EventoPresenciado/Monitorado & $\begin{array}{l}\text { Indique se presenciou, escutou } \\
\text { ou monitorou a emergência. }\end{array}$ & Essencial & $\begin{array}{l}\text { Registre como "sim", "não", "desconhe- } \\
\text { cido". Para "sim", indique se foi } \\
\text { monitorado ou não monitorado. }\end{array}$ \\
\hline Local do Evento & Área do hospital. & Essencial & $\begin{array}{l}\text { Registre como departamento de emergên- } \\
\text { cia (DE), centro cirúrgico, unidade de } \\
\text { cuidados intensivos, unidade } \\
\text { coronariana, recuperação pós-anestésica, } \\
\text { unidades de diagnóstico e tratamento, } \\
\text { ambulatórios, outras áreas dentro } \\
\text { do hospital. }\end{array}$ \\
\hline $\begin{array}{l}\text { Intervenções de suporte de vida } \\
\text { avançado(SVA) no local do evento } \\
\text { cardíaco }\end{array}$ & Indique as intervenções no local & Essencial & $\begin{array}{l}\text { Registre intubação endotraqueal, venti- } \\
\text { lação mecânica, acesso IV, cateterização } \\
\text { intra-arterial; medicamentos IV; } \\
\text { desfibrilador-cardioversor implantável }\end{array}$ \\
\hline Eventos cardiopulmonares prévios & $\begin{array}{l}\text { Local e número de qualquer evento cardíaco } \\
\text { completo prévio, que requereu tentativas de } \\
\text { ressuscitação; os eventos prévios devem ter } \\
\text { ocorrido por mais de } 24 \text { horas antes } \\
\text { do evento atual. }\end{array}$ & Desejável & $\begin{array}{l}\text { Registre o número dos eventos cardíacos } \\
\text { prévios nas seguintes categorias: prévio } \\
\text { fora do hospital; prévio dentro do hospi- } \\
\text { tal (antes da admissão); dentro do } \\
\text { hospital (a mesma admissão, mas somente } \\
\text { se }>24 \text { horas antes do evento atual). }\end{array}$ \\
\hline Causas da admissão & $\begin{array}{l}\text { Os detalhes e diagnósticos clínicos completos } \\
\text { podem não estar disponíveis imediatamente para } \\
\text { a equipe do Código Azul }\end{array}$ & Desejável & $\begin{array}{l}\text { Registre como cardíaco (inclui médico e } \\
\text { cirúrgico); não cardíaco, médico; cirúrgi- } \\
\text { co, de procedimento (programado/eletivo; } \\
\text { programado/não eletivo; não programa- } \\
\text { do/emergente); trauma, múltiplas razões. }\end{array}$ \\
\hline Capacidade funcional pré-evento & $\begin{array}{l}\text { Use o sistema de pontuação de Funcionamento } \\
\text { Cerebral (CPC), baseado na revisão das tabelas, } \\
\text { entrevistas à família e em informação registrada } \\
\text { no momento da admissão }\end{array}$ & Desejável & $\begin{array}{l}\text { Ver definição detalhada do sistema de } \\
\text { pontuação CPC. }\end{array}$ \\
\hline \multicolumn{4}{|l|}{ Variáveis do evento } \\
\hline Causa imediata precipitante & $\begin{array}{l}\text { Evento detonante imediato de uma parada } \\
\text { cardiorrespiratória }\end{array}$ & Essencial & $\begin{array}{l}\text { Registre como arritmia letal, isquemia/ } \\
\text { infarto do miocárdio, hipertensão, depres- } \\
\text { são respiratória, metabólica, outro, desco- } \\
\text { nhecido. A causa precipitante pode ser } \\
\text { incerta. }\end{array}$ \\
\hline Tentativa de ressuscitação & $\begin{array}{l}\text { Intervenções sobre a via aérea, compressões } \\
\text { torácicas, desfibrilação. }\end{array}$ & Essencial & $\begin{array}{l}\text { Indique sim ou não. Se sim, liste todas as } \\
\text { possibilidades usadas: somente via aérea, } \\
\text { somente desfibrilação, somente compres- } \\
\text { sões torácicas. }\end{array}$ \\
\hline Condição inicial da ressuscitação & $\begin{array}{l}\text { Condição do paciente no momento da chegada } \\
\text { do primeiro profissional médico. }\end{array}$ & Essencial & $\begin{array}{l}\text { Registre "sim/não", em caso de presença } \\
\text { de apnéia, sem pulso e inconsciência. }\end{array}$ \\
\hline Ritmo inicial & $\begin{array}{l}\text { O primeiro ritmo cardíaco monitorado registrado } \\
\text { depois do chamado de ajuda. }\end{array}$ & Essencial & $\begin{array}{l}\text { Registre como taquicardia/FV, assistolia, } \\
\text { atividade elétrica sem pulso, bradicardia. }\end{array}$ \\
\hline $\begin{array}{l}\text { Método para cronometrar eventos } \\
\text { e intervalos }\end{array}$ & $\begin{array}{l}\text { Os formulários de auditoria devem usar um } \\
\text { relógio de } 24 \text { horas. Os "intervalos" são a } \\
\text { duração do tempo entre eventos cronometrados. }\end{array}$ & Essencial & $\begin{array}{l}\text { Estabelecer uma sincronização dos reló- } \\
\text { gios no hospital. }\end{array}$ \\
\hline Anotar a hora do colapso & $\begin{array}{l}\text { Isto deve representar a hora em que a vítima foi } \\
\text { vista ou foi escutado que parou. }\end{array}$ & Essencial & $\begin{array}{l}\text { Para pacientes com telemetria, pode ser } \\
\text { evidente através do monitor de telemetria, } \\
\text { embora a ressuscitação não possa começar } \\
\text { até que o paciente colapsado seja locali- } \\
\text { zado fisicamente; portanto, esta é a hora } \\
\text { que deve ser registrada para propósitos } \\
\text { de auditoria. }\end{array}$ \\
\hline
\end{tabular}




\begin{tabular}{|c|c|c|c|}
\hline & Definição & $\begin{array}{l}\text { Prioridade } \\
\text { (essencial/desejável) }\end{array}$ & Instruções ou Comentários \\
\hline $\begin{array}{l}\text { Hora em que foi chamada a } \\
\text { equipe de RCP }\end{array}$ & Hora de chamada da equipe de evento cardíaco. & Essencial & $\begin{array}{l}\text { Devem ser atualizados mensalmente, à } \\
\text { medida que cheguem os formulários de } \\
\text { informe de eventos cardíacos. }\end{array}$ \\
\hline Hora de chegada da equipe de RCP & $\begin{array}{l}\text { Hora de chegada do pessoal especificamente } \\
\text { responsável pela condução da ressuscitação. }\end{array}$ & Essencial & $\begin{array}{l}\text { Não se aplica aos lugares onde não se } \\
\text { necessita a equipe do Código Azul. Por } \\
\text { exemplo, nos Departamentos de Emergên- } \\
\text { cia, a equipe está constantemente presente. }\end{array}$ \\
\hline Hora de confirmação da parada & $\begin{array}{l}\text { A melhor estimativa da hora é quando o } \\
\text { profissional confirma a ausência do } \\
\text { pulso central. }\end{array}$ & Essencial & $\begin{array}{l}\text { Isto será confirmado, geralmente, pelo pri- } \\
\text { meiro profissional médico no cenário do } \\
\text { evento cardíaco. }\end{array}$ \\
\hline Hora de começo da RCP & Hora das primeiras compressões torácicas. & Essencial & $\begin{array}{l}\text { Registre a primeira pessoa que realizou } \\
\text { RCP, para propósito de auditoria. Regis- } \\
\text { tre como enfermeiro, assistente clínico, } \\
\text { médico, terapeuta respiratório, outro. }\end{array}$ \\
\hline Hora de detenção da PCR & $\begin{array}{l}\text { Hora em que a compressão do tórax se } \\
\text { interrompe e não é reiniciada. } \\
\text { Representa a hora do óbito ou a hora de RCE. }\end{array}$ & Essencial & $\begin{array}{l}\text { Para os propósitos Utstein, os começos e } \\
\text { interrupções múltiplas são desnecessá- } \\
\text { rios; informe somente o evento final. }\end{array}$ \\
\hline $\begin{array}{l}\text { Hora do primeiro choque } \\
\text { de desfibrilação }\end{array}$ & $\begin{array}{l}\text { Hora da primeira desfibrilação e das } \\
\text { subseqüentes devem ser registradas. }\end{array}$ & Essencial & $\begin{array}{l}\text { Novos desfibriladores, especialmente com } \\
\text { dispositivos que recomendam o choque, } \\
\text { possuem capacidade de documentação de } \\
\text { eventos que facilitam o registro desta } \\
\text { informacãa. }\end{array}$ \\
\hline Hora da IOT & $\begin{array}{l}\text { Hora em que se obteve via área avançada } \\
\text { (ou quando se realiza o primeiro intento). }\end{array}$ & Essencial & $\begin{array}{l}\text { O manuseio avançado da via aérea inclui } \\
\text { a intubação endotraqueal ou estratégias } \\
\text { alternativas para a via aérea (máscara } \\
\text { laríngea ou obturador esofágico). }\end{array}$ \\
\hline $\begin{array}{l}\text { Hora da primeira medicação } \\
\text { intravenosa }\end{array}$ & $\begin{array}{l}\text { Hora do término da administração da primeira } \\
\text { dose de adrenalina ou outra medicação }\end{array}$ & Essencial & $\begin{array}{l}\text { A hora, doses, via de administração de } \\
\text { todas as drogas devem ser registradas. }\end{array}$ \\
\hline Hora do RCE & $\begin{array}{l}\text { Retorno de qualquer pulso central palpável na } \\
\text { ausência de compressões torácicas. } \\
\text { Quando o registro da PA intra-arterial está } \\
\text { presente, uma } \mathrm{PA}^{3} 60 \mathrm{mmHg} \text { é equivalente a um } \\
\text { pulso central palpável. }\end{array}$ & Essencial & $\begin{array}{l}\text { Registro da hora em que se obteve o RCE. } \\
\text { Registre como sim; nunca obtido, obtido, } \\
\text { mas não sustentado. }\end{array}$ \\
\hline $\begin{array}{l}\text { Hora do fim do RCE } \\
\text { Variáveis dos resultados }\end{array}$ & $\begin{array}{l}\text { Aplicável aos pacientes que têm um RCE não } \\
\text { sustentado ou que morrem no hospital. }\end{array}$ & Essencial & $\begin{array}{l}\text { Categorize como nunca obtido, }<20 \text { min.; } \\
>20 \text { min.; }<24 \text { hs; ou }>24 \text { hs. }\end{array}$ \\
\hline Data e hora da morte intra-hospitalar & Aplicável aos pacientes com RCE $>24$ hs. & Essencial & $\begin{array}{l}\text { Permite o cálculo da estada hospitalar e } \\
\text { da sobrevida hospitalar depois do RCE. }\end{array}$ \\
\hline $\begin{array}{l}\text { Data e hora da alta hospitalar } \\
\text { ou transferência }\end{array}$ & Auto-explicativo & Essencial & $\begin{array}{l}\text { Permite cálculos de estadas para pacien- } \\
\text { tes com ressuscitação com êxito. }\end{array}$ \\
\hline Escala de coma de Glasgow & Auto-explicativo & Essencial & $\begin{array}{l}\text { Registre cada } 24 \text { hs. depois do RCE, no } \\
\text { momento da alta até que se estabilize, aos } \\
6 \text { meses e em um ano. Para pacientes que } \\
\text { falecem no hospital, registre a melhor es- } \\
\text { cala obtida. Registre pontuação separada } \\
\text { para abertura ocular, resposta verbal e res- } \\
\text { posta motora. }\end{array}$ \\
\hline $\mathrm{CPC}$ & Auto-explicativo & Essencial & $\begin{array}{l}\text { Registre, separadamente, a pontuação para } \\
\text { os } 5 \text { componentes. Registre na data de alta, } \\
\text { aos } 6 \text { meses e em um ano. Para os pacientes } \\
\text { que falecem no hospital registre o melhor } \\
\text { CPC atingido: } \\
0=\text { morte hospitalar. } \\
1=\text { bom desempenho cerebral, consciente, } \\
\text { alerta, capaz de trabalhar e levar uma vida } \\
\text { normal. Pode ter déficits psicológicos ou } \\
\text { neurológicos menores (disfagia leve, } \\
\text { hemiparesia ou anormalidades do SNC me- } \\
\text { nores) } \\
2=\text { incapacidade cerebral moderada: cons- } \\
\text { ciente, função cerebral suficiente para tra- } \\
\text { balhar em meio-período, num ambiente } \\
\text { protegido ou em atividades independen- } \\
\text { tes da vida diária (p.ex. vestir-se, viajar em } \\
\text { transporte público, preparar alimentos). } \\
\text { Pode ter hemiplegia, convulsões, ataxia, } \\
\text { disartria, disfagia ou mudanças mentais ou } \\
\text { da memória permanentes. } \\
3=\text { incapacidade cerebral grave: cons- } \\
\text { ciente, dependente de outros para sua vida } \\
\text { diária, devido a incapacidades da função } \\
\text { cerebral (p.ex. vive numa instituicão ou }\end{array}$ \\
\hline
\end{tabular}




\begin{tabular}{|c|c|c|c|}
\hline & Definição & $\begin{array}{l}\text { Prioridade } \\
\text { (essencial/desejável) }\end{array}$ & Instruções ou Comentários \\
\hline Hora de acordar & $\begin{array}{l}\text { Pacientes considerados conscientes, sem } \\
\text { responder apropriadamente a ordens, com } \\
\text { frases verbais espontâneas, fazendo contato } \\
\text { apropriado com os olhos, respostas motoras } \\
\text { apropriadas ou que se apresenta } \\
\text { consciente e orientado. }\end{array}$ & Essencial & $\begin{array}{l}\text { em casa com esforço familiar excepcional). } \\
\text { Tem, pelo menos, uma cognição limitada; } \\
\text { inclui uma ampla gama de anormalidades } \\
\text { cerebrais, desde paralisias à incapacidade } \\
\text { de comunicar-se } \\
\text { 4= Comatoso, estado vegetativo:não } \\
\text { consciente; inconsciente de seu meio am- } \\
\text { biente, sem interação cognitiva, verbal ou } \\
\text { sociabilidade. } \\
5=\text { morte cerebral/ candidato a doação de } \\
\text { órgãos. } \\
\text { Registre com intervalos, em horas, desde a } \\
\text { parada ao despertar. Um intervalo de } 6-24 \\
\text { hs, pode ser usado, quando o evento de } \\
\text { acordar é impreciso. }\end{array}$ \\
\hline Vivo aos 6 meses, 1 ano & Auto-explicativo & Essencial & $\begin{array}{l}\text { Registre como sim (somente sim é confir- } \\
\text { mado por um meio confiável), não ou des- } \\
\text { conhecido. }\end{array}$ \\
\hline Data da morte após alta hospitalar & $\begin{array}{l}\text { Aplicável aos enfermos que morrem depois } \\
\text { de internados. }\end{array}$ & Essencial & $\begin{array}{l}\text { Registre quando possível. Indique a fon- } \\
\text { te de informação. }\end{array}$ \\
\hline Causa principal de morte & $\begin{array}{l}\text { Aplica-se a todos os pacientes que faleceram } \\
\text { depois da alta. }\end{array}$ & Essencial & $\begin{array}{l}\text { Registre como cardíaca, outras causas } \\
\text { médicas, traumas ou outros. Agregue os } \\
\text { códigos ICD-10-CM, quando for possí- } \\
\text { vel. Indique a fonte de informação da cau- } \\
\text { sa de morte (registro médico, certificado } \\
\text { de autopsia ou outros) }\end{array}$ \\
\hline Mecanismo imediato de morte & $\begin{array}{l}\text { Aplica-se a todos os pacientes que morreram } \\
\text { depois da alta. }\end{array}$ & Essencial & $\begin{array}{l}\text { Registre as mortes cardíacas súbitas, } \\
\text { infarto do miocárdio agudo, ICC, AVC, } \\
\text { traumas, outras causas médicas } \\
\text { ou desconhecidas. }\end{array}$ \\
\hline \multicolumn{4}{|c|}{$\begin{array}{l}\text { SVA: suporte de vida avançado; PA: pressão arterial; ICC: insuficiência cardíaca congestiva; SNC: sistema nervoso central; CPC: categoria de performance cerebral } \\
\text { RCP: ressuscitação cardiopulmonar, ACV: acidente vascular cerebral; ICD-10-CM: classificação internacional de doenças, } 10^{\mathrm{a}} \text { ed; IV: intravenoso; RCE: retorno à } \\
\text { circulação espontânea. }\end{array}$} \\
\hline
\end{tabular}

\section{Referências}

1. ILCOR Members Organizations, Guidelines 2000 for Cardiopulmonary Resuscitation and Emergency Cardiovascular Care. Circulation 2000; 102 (suppl-I): 86-171.

2. SafarP, Escarrraga LA, Elam JOA comparison of the mouth-to-mouth and mouthto-airway methods of artificial respiration with the chest-pressure arm-lift methods. N Eng J Med.1958; 258: 671-77.

3. Elam JO, Greene DG, Brown ES, Clements JÁ, Oxygen and carbon dioxide exchange and energy cost of expired air resuscitation. JAMA.1958; 167: 328-41.

4. Kouwenhoven W.B.; Jude J.R.; Knickerbocker G.G. Closed-chest cardiac massage. JAMA, 1960; 173: 94-7.

5. Zoll PM, Linenthal AJ, Gibson W, Paul MH, Normal LR. Termination of ventricular fibrillation in man by externally applied eletric countershock. $\mathrm{N}$ Engl J Med. 1956; 254: 727-32.

6. King D, Davies KN, Cope Cs, Silas JH. Survey of cardiac arrest and cardiac arrest trolleys in a district general hospital. Br J Clin Pract 1994; 48: 248-50.

7. Dyson E,Smith GB.Common Faults in resuscitation equipment -guidelines for checking equipment and drugs used in adult cardiopulmonary resuscitation. Resuscitation 2002; 55: 137-49.

8. Peterson MW, Geist LJ, Schwartz DA et al. Outcome after cardiopulmonary resuscitation in a medical intensive care unit..Chest 1991; 100: 168-74.

9. Smith DL, Kim K, Cairs BA, Fakhry SM, Meyer AA,. Prospective analysis of outcome after cardiopulmonary resuscitation in critically ill surgical patients. J Am Coll Surg 1995; 180: 488-9.

10. Cummins RO, Chamberlain D, et al. Recommended Guidelines for Reviewing, Reporting and Conducting Research on In-Hospital Resuscitation: The InHospital "UTSTEIN STYLE": A statement for Healthcare Professionals from the American Heart Association, The European resuscitation Council, The Heart and Stroke Foundation of Canada, The Australian Resuscitation Council, and the Resuscitation Councils of Southern Africa. Circulation 1997; 95: 2213-39.
11. ECC Handbook of Emergency Care for Healthcare Providers, Philadelphia 1a Ed, 1998, p. 1997-9.

12. Recommended guidelines for uniform reporting of data from out-of-hospita cardiac arrest: the Utstein style. Prepared by a task force of representatives from the European Resuscitation Council. American Heart Association, Heart and Stroke Foudation of Canada, and Australian Resuscitation Council. Resuscitation 1991; 22: 1-26.

13. Chamberlain D, Cummins R, Eisenberg M, et al. Schmidt A, Dick W, trans Empfehlungen zur einheitlichen Datenerfassung bei Herzstillstand-Teil I Der Utstein-Style. Notfallmedizin. 1991; 17: 510- 18.

14. Chamberlain D, Cummins R, Eisenberg M. et al. Carli P, Riuo B, Barriot P, Lambert $\mathrm{Y}$, trans. Recommendation pour une description uniforme des donnees concernant l'arrest cadiaque extra-hospitalier: le style d'Utstein. Eur J Emergencies 1991; 4: 402-23.

15. Chamberlain D, Cummins R, Eisenberg M, et al. Recommended guidelines for uniform reporting of data on out-of-hospital cardiac arrest: the Utstein Style. Intensivmedizin und Notfallmedizin 1991.

16. Recommended guidelines for uniform reporting of data from aut-of-hospital cardiac arrest (new abridged version): the Utstein style. The European Resuscitation Council. American Heart Association, Heart and Stroke Foundation of Canada, and Australian Resuscitation Council. Br Heart J 1992; 67: 325-33.

17. Chamberlain D, Cummins RO. Recommended guidelines for uniform reporting of data from out-of-hospital cardiac arrest: the Utstein style. The European Resuscitation Council. American Heart Association, Heart Stroke Foundation of Canada, and Australian Resuscitation Council Eur J Anaesthesiol 1992; 9 245- 56.

18. Cummins RO, Chamberlain DA, Abramson NS, Allen M, Baskett P, Becker L, 
Bossaert L, Delooz H, Dick W, Eisenberg M, et al. Recommended guidelines for uniform reporting of data from out-of-hospital cardiac arrest: the Utstein Style. Task Force of the American Heart Association, the European Resuscitation Cpuncil, the Heart and Stroke Foundation of Canada, and the Australian Resuscitation Council. Ann Emerg Med 1991; 20: 861-74.

19. Cummins RO, Chamberlain DA, Abramson NS, Allen M, Baskett PJ, Becker L, Bossaert L, Delooz HH, Dick WF, Eisenberg MS, Evans TR, Holmberg S, Kerber R, Mullie A, Ornato JP, Sandoe E, Skulberg A, Tunstall-Podoe H, Swanson R, Thies WH. Recommended guidelines for uniform reporting of data from out-ofhospital cardiac arrest: the Utstein Style. A statement for health professionals from a task force of the American Heart Association, the European Resuscitation Council, the Heart and Stroke Foundation of Canada, and the Australian Resuscitation Council. Circulation 1991; 84: 960-75.

20. Zaritsky A, Nadkarni V, Hazinski MF, Foltin G, Quan L, Wringht J, Fiser D, Zideman D, O'Malley P, Chameides L, Cummins RO. Recommended guidelines for uniform reporting of pediatric advanced life support: the pediatric Utstein style. American Academy of Pediatrics, American Heart Association and the European Resuscitation Council Ann Emerg Med 1995; 26: 487-503. (a) statement for health professionals from a task force of the American Academy of Pediatrics, the American Heart Association, and the European Resuscitation Council. Pediatrics 1995; 96(pt 1): 765-779 (b) A statement for healthcare proffesionals from a task force of the American Academy of Pediatrics, the American Heart Association, and the European Resuscitation Council. Resuscitation 1995; 30: 95-115.

21. Idris AH, Becker LB, Ornato JP, Hedges JR, Bircher NG, Chandra NC, Cummins RO, Dick W, Ebmeyer U, Halperin HR, Hazinski MF, Kerber RE, Kern KB, Safar P, Steen PA, Swindle MM, Tsitlik JE, von Planta J, von Planta M, Wears RL, Weil $\mathrm{MH}$. Utstein-style guidelines for uniform reporting of laboratory CPR: a statement for healthcare professionals from a task force of the American Heart Association, the American College of Emergency Physicians, the American College of Cardiology, the Heart and Stroke Foundation of Canada, the Institute of Critical Care Medicine, the Safar Center for Resuscitation Research, and the Society for Academic Emergency Medici-ne. Circulation 1996; 94: 2324-36.

22. The Asilomar Working Group on Recommendations for Reporting of Clinical Trials in The Biomedical Literature. Checklist of information for inclusion in reports of clinical trials. Ann Intern Med 1996; 124: 741-3.

\section{Anexo 1: Planilha de Registro de Ressuscitação Cardiopulmonar Intra-Hospitalar}

\section{Registro de Ressuscitação Cardiopulmonar Intra-hospitalar}

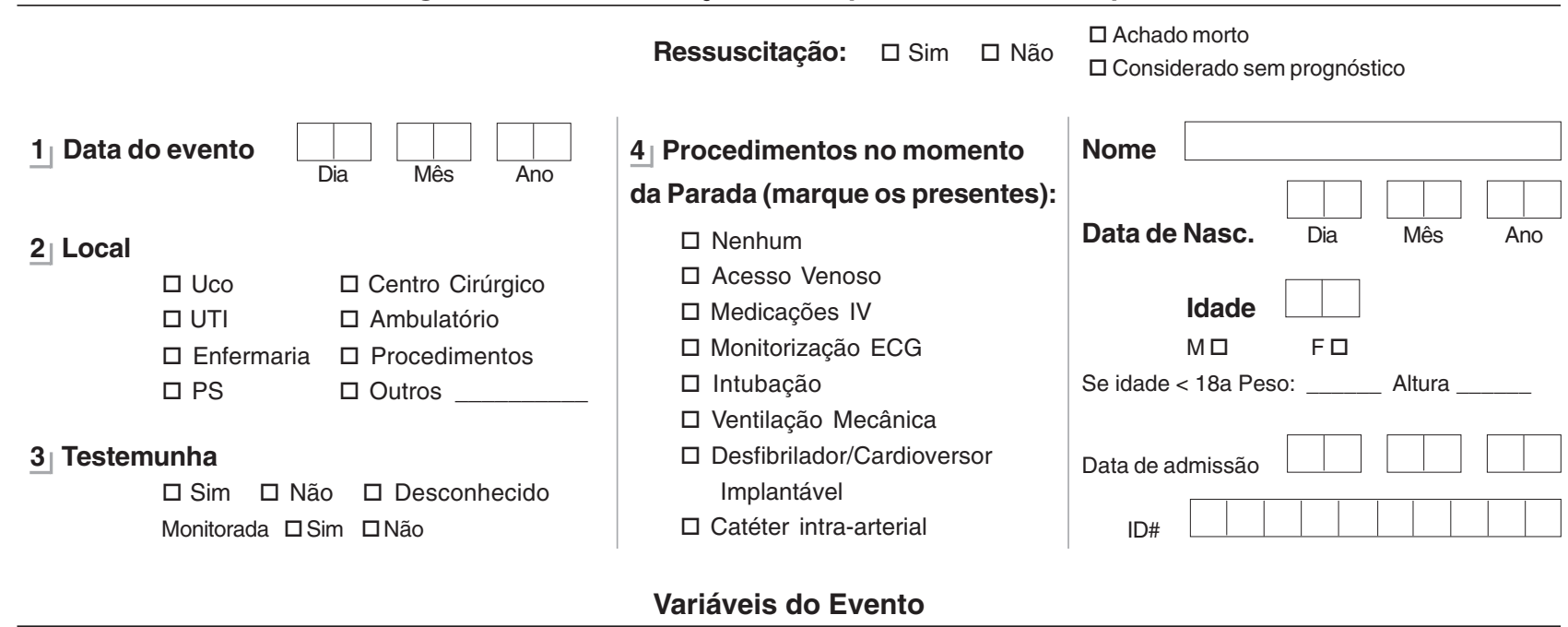

5 Hora dos eventos (as áreas sombreadas são necessárias para calcular os intervalos da cadeia de sobrevivência intrahospitlar da AHA e ERC)

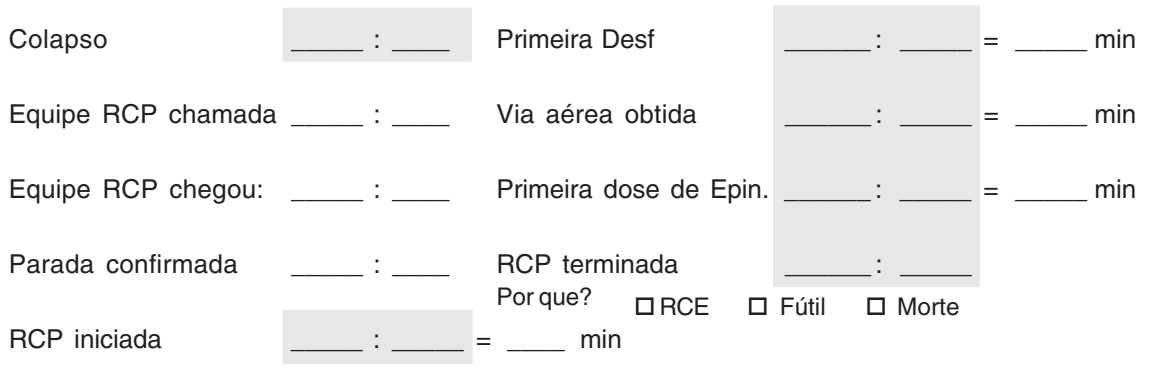

\section{Circulação espontânea: \\ $\square$ Retornou}

(se sim Hora de RCE)

$\square$ Nunca atingida

$\square$ RCE não sustentada

$$
\begin{aligned}
& \square \leq 20 \mathrm{~min} \\
& \square>20 \mathrm{~min} \text { e } \leq 24 \text { horas } \\
& \square>24 \text { horas }
\end{aligned}
$$

\section{Condição inicial}

Conciente? $\square$ Sim

Respirando? $\square \mathrm{Sim}$

Pulso?

$\square \operatorname{Sim}$ $\square$ Não

$\square$ Não

$\square$ Não

\section{Ritmo inicial}

$\square \mathrm{FV}$

$\square T V$

$\square$ AESP

$\square$ Bradicardia

$\square$ Assistolia

$\square$ Ritmo com perfusão
8 Se tentada ressuscitação, marque:

$\square$ Compressão torácica

․ Desfibrilação

$\square$ Via área
9 Causa imediata

$\square$ Arritmia letal

$\square$ Hipotensão

$\square$ Depressão respiratória

Metabólica

$\square$ IAM ou Isquemia

$\square$ Desconhecida

$\square$ Outra 
Tratamento durante a ressuscitação (abaixo):

\begin{tabular}{|c|c|c|c|c|c|c|}
\hline Horário & Comentários & S. Vitais & Ritmo & Desfib/J & Medicações & Dose/Via \\
\hline & & & & & & \\
\hline & & & & & & \\
\hline & & & & & & \\
\hline & & & & & & \\
\hline & & & & & & \\
\hline & & & & & & \\
\hline & & & & & & \\
\hline & & & & & & \\
\hline & & & & & & \\
\hline
\end{tabular}

Variáveis do Seguimento

10 Quando acordou? Hora

11 Seguimento no hospital (marque um):

$$
\square \text { Alta Hora __ : }
$$$$
\text { Dia }
$$

Dia

alta: $\square$ outro hospital

$$
\begin{aligned}
& \square \text { Casa } \\
& \square \text { Casa de repouso } \\
& \square \text { Outro }
\end{aligned}
$$

$\mathrm{CPC}$ da alta $=$

Glasgow Total $=$ R _ R _ $\mathrm{RM}$

Morte no Hospital (RCE > 24 horas)

Dia

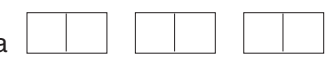

12 Vivo após 6 meses:

$\square \operatorname{Sim}\left({ }^{*} \mathrm{CPC}\right)=$

$\square$ não (data da morte)

$\square$ desconhecido
13. Vivo após 1 ano:
$\square \operatorname{Sim}\left({ }^{*} C P C\right)=$
$\square$ não (data da morte)
$\square$ desconhecido

14 Se morreu, principal causa de óbito:
$\square$ ICO
$\square$ Câncer
$\square$ Trauma
$\square$ Outra Causa

15. CID 10

16 Fonte de Informação (para 14 e 15):

$\square$ Prontuário

$\square$ Atestado médico

$\square$ Médico da família

$\square$ Autópsia

$\square$ Outro

Informações Adicionais

\section{Quem realizou a ressuscitação}

$\square$ Médico $\quad \square$ Auxiliar de enfermagem

$\mathrm{N}^{\circ}$ de médicos envolvidos no atendimento treinados em ACLS

$\mathrm{N}^{\circ}$ de enfermeiros envolvidos no atendimento treinados em ACLS
18 Horário da IOT

19. Outras tentativas de ressuscitação (se há mais de 24 horas da atual):

$\square \operatorname{Sim} \square$ Quantas

$\square$ Não Data da primeira:

20. Diagnósticos da internação:

21 Diagnósticos antes da PCR:

22 Nome do Médico:

23. Realizou alguns destes cursos:

$\square$ ACLS Provider

$\square$ ACLS Instructor

$\square$ BLS Provider

$\square$ BLS Instructor $\square$ Outros:

especifique 


\section{Anexo II: Avaliação dos Carros de Emergência}

Unidade

Número de leitos

Número de carrinhos na unidade

Disposição dos carrinhos na unidade

Material disponível nas seguintes gavetas:

a) Bandeja superior

b) Gaveta 1

c) Gaveta 2

d) Gaveta 3

e) Parte Inferior

f) Laterais

Observações Gerais 